Tropical Journal of Pharmaceutical Research October 2011; 10 (5): 619-629

(C) Pharmacotherapy Group,

Faculty of Pharmacy, University of Benin

Benin City, 300001 Nigeria.

All rights reserved.

Available online at http://www.tjpr.org

Research Article

http://dx.doi.org/10.4314/tjpr.v10i5.11

\title{
The Construct Validity of an Instrument for Measuring Type 2 Diabetes Self-Care Knowledge in Nigeria
}

\author{
Maxwell O Adibe*, Cletus N Aguwa and Chinwe V Ukwe \\ Department of Clinical Pharmacy and Pharmacy Management, Faculty of Pharmaceutical Sciences, University of \\ Nigeria, Nsukka, Nigeria
}

\begin{abstract}
Purpose: To develop an instrument (DSCKQ-30) for measuring type 2 diabetic patients' knowledge of self-care practices.

Methods: A 30-item questionnaire (DSCKQ-30) consisting of close ended questions was developed for this study. DSCKQ-30 was self administered to a cross-section of randomly selected 400 ambulatory adult diabetic patients ( $\geq 18$ years), who were attending endocrinology clinics at the hospitals included in this study. The sex distribution for female and male was 56.7 and $43.3 \%$ respectively. Factor analysis and item analysis were performed to test the construct validity and reliability of the instrument. Item performance was measured by item discrimination (item-to-total correlation) and percent correctness (\%C).

Results: The response rate was $78.5 \%$. Factor analysis identified three scales of knowledge of self-care management. Chronbach's alpha of the 30 questionnaire items was found to be 0.89 . The item-to-total correlation coefficients and ranges for component 1 - 3 were $0.36(0.25-0.48), 0.28(0.23-0.35)$, and $0.34(0.23-0.41)$, respectively, with overall average of $0.33(0.23-0.48)$. Items percent correctness (\% C) ranged from 16.7 to $86.7 \%$ with an overall average of $55.6 \%$. Item factor loadings averaged 0.62 for the total items; averages of the three scales ranged from 0.59 to 0.68 .

Conclusion: The DSCKQ-30 provided a quantitative measure of patient's knowledge of self-care practices.
\end{abstract}

Keywords: Diabetes self-care knowledge, DSCKQ-30, Knowledge instrument, Nigeria.

*Corresponding author: E-mail: maxolpharmacia@yahoo.com; maxwell.adibe@unn.edu.ng; Tel: +2348037781479 


\section{INTRODUCTION}

Diabetes mellitus (DM) is associated with considerable morbidity and mortality [1]. Diabetes is also a major risk factor for cardiovascular disease, stroke, and kidney failure [2]. In Africa, DM probably has the highest morbidity and mortality rates of all chronic non infective diseases [3]. In Nigeria, where healthcare services and accessibility are poor, DM is associated with a high disease burden. Unfortunately, in Nigeria, communicable diseases remain the priority health condition for the Ministry of Health. Most of the reports on morbidity and mortality rates of diabetes in Nigeria were made in the 1960s and 1970s and therefore may not reflect the current situation $[4,5]$.

Self-care in diabetes has been emphasized in the recent standard treatment guidelines of Nigeria [6] and other white papers, 'Our Health, Our Care, Our Say' $[7,8]$. People with diabetes are now encouraged to take part in structured education programs, which will have positive results on blood glucose and bring about reduction in complication rates. This will enable patients with diabetes to become more responsible and successful in self managing their condition. Pharmacists and other healthcare team members have their role as well, providing advice, services and support to enable people with diabetes care for themselves and get maximum benefit from their treatment $[9,10]$. There are many good reasons to take action towards self management of diabetes because it might improve the patients' quality of life. With good self-management in the future, the patients are likely to stay healthy and prevent or delay problems that can involve heart, blood vessels, eyes, kidneys, and nerves $[7,8]$.

Behavioural change focuses on nutrition, physical activity and psychosocial coping skills. Self-monitoring of blood glucose (SMBG) is also considered an important aspect of diabetes self-management [11]. Studies have demonstrated that knowledge about medications, diet, exercise, home glucose monitoring, foot care, and treatment modifications is necessary to effectively selfmanage diabetes [12,13]. Although knowledge alone does not guarantee requisite behaviour modifications or effective self-management [14], the assessment of diabetes self-care related knowledge is an important first step from which to individualize diabetes education programs and make evaluations of their effectiveness [15].

The need to improve self-care knowledge and control of diabetes mellitus has necessitated the incorporation of measures to be taken to improve the quality of life of diabetic patients in the National Standard Treatment Guidelines (STGs) by the Nigeria Ministry of Health [6]. Development of an instrument for measuring diabetic patients' knowledge of self-care practices can assist in targeting public health efforts to reduce complications. The above issues informed the aim of this study which was to develop an instrument (DSCKQ-30) for measuring type 2 diabetic patients' knowledge of self-care practices in Nigeria.

\section{METHODS}

\section{Instrument development}

A 30-item Diabetes Self-care Knowledge Questionnaire (DSCKQ-30) consisting of close-ended questions was developed for the survey. Items included in the instrument covered the contents of STGs of Nigeria, 2008 [6]. The STGs stressed the need for diabetes self monitoring education in areas of diet, physical activities, drug treatment, recognition of adverse effects of diabetes drugs, treatment of co-morbidities, diabetic foot problems, diabetes in pregnancy, acute and chronic complications and need for compliance and adherence to diabetes management by the patients.

Fifteen questions were 'true' questions while the remaining fifteen were 'false' questions. Both 'true' questions and 'false' questions were dispersed evenly throughout the questionnaire. To avoid difficulties previously 
reported with using Likert-type scales [16], potential response choices for the DSCKQ-30 were 'Yes' and 'No'. Respondents were requested to tick 'Yes' if the statement posed in the questions was true and 'No' if the statement posed in the questions was false. Items were scored as correct or incorrect, and the correct items were summed to attain a total score. High total score correlates with high level of self-care activities knowledge of the patients and verse versa.

The DSCKQ-30 is a relatively easy-to-use measure when compared with an existing diabetes self-care measure developed by Toobert et al [17]. It is unique, simple and specific for measuring diabetes self-care knowledge. The items were written in simple language to aid patients' understanding and in a manner that could be easily read. DSCKQ-30 embodies Nigerian local contents issues. In addition to questions asked to assess patients' knowledge of self-care, the survey included questions on demographic variables of the respondents such as age, sex, marital status, education level, occupation, income per month, years with diabetes, type of hospital facility and having family members, relatives or friends with diabetes.

This investigation was carried out in five states of south-eastern Nigeria. Southeastern Nigeria is one of the six geo-political zones in Nigeria. Areas in this zone have the same culture, economic, religion, social life and political ideology. It is the native home of the Igbos. (Igbos are people speaking Igbo language which is one of the three major languages in Nigeria). The population of the zone is $16,381,729$ [18]. Health care facilities studied included four tertiary and six secondary hospitals.

\section{Sampling technique}

Multi-stage sampling was employed; four tertiary hospitals were randomly selected from eleven (11) tertiary hospitals in the south-eastern zone. One secondary hospital each was randomly selected from four states except Enugu where two secondary hospitals were randomly selected because of its status in south-east. Enugu was the capital of old eastern region from which these present five states were created and Enugu has four out of eleven tertiary hospitals in the zone. In addition, it is still serving as headquarters to south-eastern Nigeria.

\section{Study design}

This was a cross sectional study. Four hundred (400) adult patients that satisfied the inclusion criteria were randomly selected following their consent. Type 2 diabetic patients were eligible if they were aged 18 and above, able to read and write English, and not too ill to complete the questionnaire. The questionnaire was pilot-tested using 47 type 2 diabetic patients, to establish the items' clarity. After the pretest, the instrument was slightly modified and administered to the selected ambulatory diabetic patients who were attending diabetic clinics at the hospitals included in this study. The questionnaire was completed by selfadministration.

Investigators briefed the respondents on the purpose of the study and oral consent was obtained from the respondents. Ethical approval for the study was obtained from the individual hospital institutional review board. Confidentiality and anonymity of the patients' information were maintained during and after the study.

\section{Data collection}

Administration and retrieval of questionnaires were continuous for five weeks between $2^{\text {nd }}$ November and $6^{\text {th }}$ December, 2008. Nonresponders were interviewed and reasons given for their non participation ranged from lack of time to lack of interest. The time taken to complete the questionnaire ranged from 15 to $20 \mathrm{~min}$. 


\section{Analysis of data}

The data were sorted, coded and entered into Statistical Package for the Social Sciences for Windows 14.0 (SPSS Inc., Chicago, IL) and subsequently analyzed. Results were presented as mean $\pm S D$ and $95 \%$ Confidence Interval (Cl) and percentages. Relationships between the demographic profile and responses were explored using Student's t-test and one-way ANOVA. Skipped questions analysis was explored using Chi-Square tests. Risk of skipping questions correlated with misunderstanding of questions in the questionnaire and verse versa. Inferential statistics were calculated with the aid of GraphPad Instat 3; hence a Pvalue of less than 0.05 was interpreted as significant.

A Kaiser-Meyer-Olkin measure of sampling adequacy was calculated to determine the extent to which the variables belonged together and were appropriate for factor analysis. Factor analysis was performed to test the construct validity of the instrument using principal component extraction with Direct Oblimin rotation. Listwise deletion was used to handle missing values in the factor analysis. Components selected for rotation had eigenvalues greater than 1. The internal consistency of the scales was assessed using Cronbach's $\alpha$.

Item performance was measured by item discrimination (item-to-total correlation) and percent correctness (\%C) (percent of respondents answering the item correctly) and was expressed as in Eq 1.

$C(\%)=(A / B) \times 100$

where $A$ is the number of respondents who answered the item correctly and B is the total number of respondents who attempted the item 'question'.

\section{RESULTS}

A total of 314 out of 400 questionnaires distributed were received, yielding a response rate of $78.5 \%$. Three hundred and three (303) questionnaires were completely filled, thus were used in factor analysis, indicating that 11 respondents did not answer at least one question. Patients who stopped at primary, secondary and tertiary education accounted for 4 (36.4\%), 5 (45.5\%) and 2 $(18.2 \%)$ of the unanswered questions respectively. Having family members, relatives or friends with diabetes (t-test $=$ 6.606; $p<0.0001)$ and years with diabetes ( $F$ $=3.453 ; p=0.0169$ ) were significantly associated with mean score of patients' knowledge of self-care practices (Table 1).

The Kaiser-Meyer-Olkin measure of sampling adequacy for the factor analysis was 0.87 . Items were included if they maintained itemto-total correlations greater than or equal to 0.25 [19]. However, some items that did not meet this criterion were retained if the items reflected content critical to the self-care management, and had little variability (i.e., if percent correctness $(\% \mathrm{C})$ was $>80 \%$ (percentage of respondents who answered the item correctly).

Principal component extraction method using Direct Oblimin rotation and the criterion of an eigenvalue greater than 1.0, identified three components. However, the scree plot indicated a break after the fourth components (eigenvalue $=0.61$ ). Chronbach's alpha for the 30 questionnaire items was found to be 0.89 . The first scale consisted of the 18 items with loadings on component 1 . Most of these items related to the dimensions of modifiable lifestyles and was labelled modifiable lifestyles. The internal consistency of this scale, as measured by Cronbach's $\alpha$, was 0.82 (Table 2a).

The second scale comprised 8 items with loadings on component 2. Most of these items related to the dimensions of knowledge of compliance and adherence to self-care practice and was labelled compliance and adherence to self-care practices. The internal consistency of this scale, as measured by Cronbach's $\alpha$, was 0.74 (Table 2b). 
Table 1: Association of knowledge mean score and patients' demographic characteristics

\begin{tabular}{|c|c|c|c|c|c|}
\hline Characteristics & Frequency & $\%$ & Mean Score & \pm S.D & $95 \% \mathrm{Cl}$ \\
\hline \multicolumn{6}{|c|}{ Age (Years) $\quad(n=314) \quad F=1.356 ; P=0.2592$} \\
\hline $18-35$ & 45 & 14.3 & 24.3 & 4.65 & $22.902-25.698$ \\
\hline $36-50$ & 116 & 36.9 & 23.4 & 5.34 & $22.417-24.383$ \\
\hline$>50$ & 153 & 48.7 & 22.9 & 5.04 & $22.101-23.699$ \\
\hline $\operatorname{Sex}(n=314)$ & \multicolumn{5}{|c|}{ t-test $=1.956 ; p=0.0513$} \\
\hline Female & 178 & 56.7 & 24.1 & 5.71 & $23.261-24.939$ \\
\hline Male & 136 & 43.3 & 22.9 & 4.93 & $22.071-23.729$ \\
\hline \multicolumn{6}{|c|}{ Marital Status $\left(n=310^{*}\right) \quad F=1.573 ; p=0.1959$} \\
\hline Single & 32 & 10.3 & 22.6 & 5.03 & $20.786-24.414$ \\
\hline Married & 124 & 40.0 & 21.5 & 4.69 & $20.674-22.326$ \\
\hline Widowed & 137 & 44.2 & 20.8 & 4.82 & $19.993-21.607$ \\
\hline Divorced & 17 & 5.5 & 22.3 & 5.34 & $19.554-25.046$ \\
\hline \multicolumn{6}{|c|}{ Monthly income (\#) $\{$ USD $1=N 150\}\left(n=301^{*}\right) \quad F=2.246 ; p=0.0831$} \\
\hline Less than 10,000 & 101 & 33.6 & 21.9 & 4.58 & $20.995-22.805$ \\
\hline$>10,000-30,000$ & 43 & 14.3 & 23.4 & 5.39 & $21.741-25.059$ \\
\hline$>30,000$ to 50,000 & 98 & 32.6 & 22.8 & 4.19 & $21.959-23.641$ \\
\hline$>50,000$ & 59 & 19.6 & 23.7 & 4.83 & $22.441-24.959$ \\
\hline \multicolumn{6}{|c|}{ Occupation $\left(n=307^{*}\right) \quad F=2.396 ; p=0.0683$} \\
\hline Student & 11 & 3.6 & 23.4 & 5.24 & $19.880-26.920$ \\
\hline Self-Employed & 99 & 32.3 & 20.7 & 3.83 & $19.935-21.465$ \\
\hline Employee & 59 & 18.6 & 21.8 & 4.86 & $20.533-23.067$ \\
\hline Retired & 138 & 45.0 & 20.3 & 5.42 & $19.396-21.204$ \\
\hline \multicolumn{6}{|c|}{ Educational Status $(n=314) F=2.775 ; p=0.0639$} \\
\hline Primary Education & 94 & 29.9 & 22.6 & 6.07 & $21.355-23.845$ \\
\hline $\begin{array}{l}\text { Secondary } \\
\text { Education }\end{array}$ & 163 & 51.9 & 24.2 & 5.27 & $23.391-25.009$ \\
\hline Tertiary Education & 57 & 18.2 & 23.8 & 3.58 & $22.850-24.750$ \\
\hline \multicolumn{6}{|c|}{ Duration of diabetes $\left(n=299^{*}\right) \quad F=3.453 ; p=0.0169$} \\
\hline Recently (< 1 year) & 141 & 47.1 & 22.2 & 5.43 & $21.304-23.096$ \\
\hline $1-5$ years & 59 & 19.7 & 20.6 & 4.08 & $19.537-21.663$ \\
\hline $6-10$ years & 71 & 23.8 & 23.4 & 5.70 & $22.049-24.751$ \\
\hline More than 10 years & 28 & 9.4 & 21.3 & 3.74 & $19.850-22.750$ \\
\hline \multicolumn{6}{|c|}{ Type of Hospital $(n=314) \quad$ t-test $=0.8957 ; p=0.3711$} \\
\hline Secondary & 161 & 51.3 & 23.3 & 4.15 & $22.659-23.941$ \\
\hline Tertiary & 153 & 48.7 & 23.7 & 3.74 & $23.107-24.293$ \\
\hline \multicolumn{6}{|c|}{ Have family members, relatives or friends with diabetes $\left(n=313^{*}\right) \quad$ t-test $=6$} \\
\hline Yes & 212 & 67.7 & 24.8 & 3.87 & $24.279-25.321$ \\
\hline No & 101 & 32.3 & 21.6 & 4.28 & $20.754-22.446$ \\
\hline
\end{tabular}

${ }^{*}$ Number reporting may be $<314$ due to non-response to an item 
Adibe et al

Table 2a: Factor and Items analysis showing Component 1: Modifiable Lifestyles (18 Items)

\begin{tabular}{|c|c|c|c|c|c|}
\hline $\begin{array}{l}\text { Item } \\
\#\end{array}$ & Questions & $\begin{array}{l}\text { No. of } \\
\text { Resp }\end{array}$ & $\% \mathrm{C}^{\mathrm{a}}$ & ITTC $^{b}$ & Loadings \\
\hline 4 & $\begin{array}{l}\text { Blood glucose level should be measured before and } \\
\text { after every physical activity. }\end{array}$ & 384 & 23.2 & 0.36 & 0.82 \\
\hline 1 & $\begin{array}{l}\text { Fasting blood sugar (FBS) test can be used to monitor } \\
\text { blood sugar control of } 2-3 \text { months. }\end{array}$ & 382 & 36.6 & 0.44 & 0.78 \\
\hline 21 & $\begin{array}{l}\text { A person with diabetes should take care of his/her teeth } \\
\text { and brush and floss his/her teeth every day. }\end{array}$ & 384 & 63.3 & 0.32 & 0.74 \\
\hline 20 & $\begin{array}{l}\text { Tight elastic hose or socks are not bad for a person with } \\
\text { diabetes. }\end{array}$ & 384 & 43.5 & 0.30 & 0.72 \\
\hline 26 & $\begin{array}{l}\text { Self blood glucose monitoring (SBGM) enables a person } \\
\text { with diabetes to monitor and react to changes in his/her } \\
\text { blood sugar levels. }\end{array}$ & 383 & 26.9 & 0.31 & 0.69 \\
\hline 3 & $\begin{array}{l}\text { Only the doctors should make plans on how a person } \\
\text { with diabetes can achieve his/her target goals. }\end{array}$ & 384 & 16.7 & 0.35 & 0.67 \\
\hline 7 & $\begin{array}{l}\text { Maintaining a healthy weight is not important in } \\
\text { management of diabetes. }\end{array}$ & 382 & 46.6 & 0.36 & 0.66 \\
\hline 25 & $\begin{array}{l}\text { Self blood glucose monitoring (SBGM) allows doctor and } \\
\text { other healthcare team to gather data for treatment } \\
\text { planning. }\end{array}$ & 384 & 33.3 & 0.42 & 0.64 \\
\hline 23 & $\begin{array}{l}\text { No person should check blood sugar and blood pressure } \\
\text { of a diabetic patient except qualified medical doctor and } \\
\text { other health personnel in the hospital. }\end{array}$ & 384 & 73.2 & 0.43 & 0.61 \\
\hline 5 & $\begin{array}{l}\text { Having physical activity for } 20-30 \text { minutes per session at } \\
\text { least } 3 \text { days per week is essential. (Example of physical } \\
\text { activities: Brisk walking, house activities, climbing } \\
\text { staircase). }\end{array}$ & 384 & 30.2 & 0.40 & 0.59 \\
\hline 24 & $\begin{array}{l}\text { A person with diabetes should report any change in his } \\
\text { eyesight to his doctor. }\end{array}$ & 383 & 76.8 & 0.48 & 0.56 \\
\hline 18 & $\begin{array}{l}\text { There should be mutual agreement between a person } \\
\text { with diabetes and the doctor if he/she cannot change a } \\
\text { particular lifestyle. }\end{array}$ & 384 & 66.7 & 0.46 & 0.53 \\
\hline 19 & $\begin{array}{l}\text { A person with diabetes should take extra care of his/her } \\
\text { feet especially when cutting his/her toenails }\end{array}$ & 384 & 20.1 & 0.38 & 0.51 \\
\hline 6 & $\begin{array}{l}\text { Regular exercise does not reduce the need for insulin or } \\
\text { other diabetic drugs. }\end{array}$ & 380 & 23.4 & 0.38 & 0.49 \\
\hline 8 & $\begin{array}{l}\text { A person with diabetes should only ask for help when } \\
\text { he/she feels sick from his/her healthcare team. } \$\end{array}$ & 384 & 73.2 & 0.39 & 0.47 \\
\hline 17 & $\begin{array}{l}\text { At the initiation of insulin therapy for a person with } \\
\text { diabetes who may require it, appropriate advice on Self } \\
\text { Blood Glucose Monitoring (SBGM) and diets should be } \\
\text { given to the person. }\end{array}$ & 384 & 33.6 & 0.38 & 0.46 \\
\hline 9 & Cigarette smoking can worsen diabetes & 384 & 30.7 & 0.33 & 0.45 \\
\hline 29 & $\begin{array}{l}\text { Monitoring blood pressure is not as important as } \\
\text { monitoring blood glucose in a person with diabetes. }\end{array}$ & 381 & 66.4 & 0.36 & 0.42 \\
\hline \multicolumn{2}{|c|}{ Scale Average (Range) } & & $\begin{array}{l}43.6 \\
(16 .- \\
76.8)\end{array}$ & $\begin{array}{l}0.38 \\
(0.30- \\
0.48)\end{array}$ & $\begin{array}{l}0.60 \\
(0.42-0.82)\end{array}$ \\
\hline
\end{tabular}

${ }^{a}$ Percent correctness ${ }^{b}$ Item-to-Total Correlation

"Only the highest loadings are presented in rank order.

${ }^{s_{M e m b e r s}}$ of health care team are Doctors, Pharmacists, Foot Doctors, Eye Doctors, Nurses, Dentists, Dietitians, Diabetes Educators, Mental Health Counselors, Social Workers, Friends and Family.

${ }^{¥}$ Total number of Respondents who attempted the item 'question' 
Table 2b: Factor and Items analysis showing Component 2: Adherence (8 Items)

\begin{tabular}{|c|c|c|c|c|c|}
\hline $\begin{array}{l}\text { Item } \\
\#\end{array}$ & Questions & $\begin{array}{l}\text { No. of } \\
\text { Resp }\end{array}$ & $\% \mathrm{C}^{\mathrm{a}}$ & ITTC $^{b}$ & Loadings \\
\hline 14 & $\begin{array}{l}\text { Regular medical checkups are not essential when a } \\
\text { person with diabetes is feeling well. }\end{array}$ & 384 & 82.0 & 0.28 & 0.84 \\
\hline 2 & $\begin{array}{l}\text { Dietary instructions should be written out, even if the } \\
\text { person with diabetes is illiterate: someone at home } \\
\text { should be available to interpret it for him/her. }\end{array}$ & 384 & 81.8 & 0.26 & 0.75 \\
\hline 13 & $\begin{array}{l}\text { Instructions about drugs and other self-care practices } \\
\text { should not be strictly followed. }\end{array}$ & 384 & 70.0 & 0.29 & 0.74 \\
\hline 15 & $\begin{array}{l}\text { Taking low dose Aspirin (Vasoprin } \AA \text {, Emprin } \AA \text { ) tablet } \\
\text { every day decreases risk of having heart attack and } \\
\text { stroke. }\end{array}$ & 381 & 63.3 & 0.31 & 0.72 \\
\hline 10 & $\begin{array}{l}\text { A person with diabetes taking medicines when he/she } \\
\text { feels good is waste of money. }\end{array}$ & 384 & 89.8 & 0.45 & 0.72 \\
\hline 11 & $\begin{array}{l}\text { Being drunk while on diabetic drugs is not a serious } \\
\text { problem. }\end{array}$ & 384 & 76.6 & 0.27 & 0.64 \\
\hline 12 & $\begin{array}{l}\text { Diet and exercise are not as important as medication } \\
\text { in control of diabetes. }\end{array}$ & 384 & 33.1 & 0.35 & 0.56 \\
\hline \multirow[t]{2}{*}{16} & $\begin{array}{l}\text { Diabetes drugs are not taken throughout the life time } \\
\text { of a person with diabetes. }\end{array}$ & 380 & 63.2 & 0.37 & 0.47 \\
\hline & Scale Average (Range) & $\begin{array}{l}69.98 \\
(33.1- \\
89.8)\end{array}$ & $\begin{array}{l}0.32 \\
(0.26- \\
0.45)\end{array}$ & $\begin{array}{l}0.68 \\
(0.47- \\
0.84)\end{array}$ & \\
\hline
\end{tabular}

${ }^{a}$ Percent correctness ${ }^{b}$ Item-to-Total Correlation "Only the highest loadings are presented in rank order. ${ }^{s}$ Members of health care team are Doctors, Pharmacists, Foot Doctors, Eye Doctors, Nurses, Dentists, Dietitians, Diabetes Educators, Mental Health Counselors, Social Workers, Friends and Family.

*Total number of Respondents who attempted the item 'question'

Table 2c: Factor and Items analysis showing Component 3: Consequences of Uncontrolled Blood Sugar Level (4 Items)

\begin{tabular}{|c|c|c|c|c|c|}
\hline Item \# & Questions & $\begin{array}{l}\text { No. of } \\
\text { Resp }\end{array}$ & $\% C^{a}$ & ITTC $^{b}$ & Loadings \\
\hline 22 & $\begin{array}{l}\text { If blood sugar is close to normal, a person } \\
\text { with diabetes is likely to have more energy, } \\
\text { feel less thirsty and urinate less often. }\end{array}$ & 384 & 56.8 & 0.34 & 0.74 \\
\hline 28 & $\begin{array}{l}\text { Prolonged high blood sugar level can } \\
\text { cause eye problem or even blindness. }\end{array}$ & 384 & 43.8 & 0.39 & 0.63 \\
\hline 30 & $\begin{array}{l}\text { Prolonged uncontrolled blood sugar level } \\
\text { can cause heart attack, stroke and kidney } \\
\text { problems. }\end{array}$ & 382 & 86.6 & 0.33 & 0.53 \\
\hline 27 & $\begin{array}{l}\text { Shaking, confusion, behavioural changes } \\
\text { and sweating are signs of high blood } \\
\text { sugar. }\end{array}$ & 379 & 26.9 & 0.41 & 0.45 \\
\hline \multicolumn{3}{|c|}{ Scale Average (Range) } & $\begin{array}{l}53.5 \\
(26.9- \\
86.6) \\
53.7 \\
(16.7- \\
89.8)\end{array}$ & $\begin{array}{l}0.37 \\
(0.33- \\
0.41) \\
\mathbf{0 . 3 6} \\
(\mathbf{0 . 2 6}- \\
\mathbf{0 . 4 8 )}\end{array}$ & $\begin{array}{l}0.59 \\
(0.45- \\
0.74) \\
\mathbf{0 . 6 2} \\
\mathbf{( 0 . 4 2 -} \\
\mathbf{0 . 8 4 )}\end{array}$ \\
\hline
\end{tabular}

${ }^{a}$ Percent correctness ${ }^{b}$ Item-to-Total Correlation "Only the highest loadings are presented in rank order.

${ }^{s}$ Members of health care team are Doctors, Pharmacists, Foot Doctors, Eye Doctors, Nurses, Dentists, Dietitians, Diabetes Educators, Mental Health Counselors, Social Workers, Friends and Family.

"Total number of Respondents who attempted the item 'question' 
The third scale had four items with loadings on component 3 . The internal consistency of third scales, as measured by Cronbach's $\alpha$, was 0.64. Most of these items in component 3 were related to the dimensions of knowledge of consequences of uncontrolled blood sugar level and were labelled consequences of uncontrolled blood sugar level. A large first scale accounted for $52.4 \%$ of the variance while the second and third scales accounted for 29.4 and $6.3 \%$ variance, respectively. The item-to-total correlation coefficients and their ranges for component 1 , component 2 , and component 3 were $0.36(0.25-0.48), 0.28(0.23-0.35)$, and $0.34(0.23-0.41)$, respectively with overall average of $0.33(0.23-0.48)$. Items percent correctness $(\% \mathrm{C})$ ranged from 16.7 to $86.7 \%$ with an overall average of $55.6 \%$. Factor loadings averaged 0.62 for the total items; averages ranged from 0.59 to 0.68 among the three subgroups (Table $2 \mathrm{c}$ ).

\section{DISCUSSION}

\section{Instrument Validity}

Validity of DSCKQ-30 was supported in following ways. Firstly, the scales identified by factor analysis were similar to the hypothesized scales. The first scale included almost all of the items developed specifically to address knowledge of modifiable lifestyles like diet, exercise, self blood glucose monitoring, foot, tooth and eye cares. The second dimension, compliance and adherence to management, includes many of the items that were originally hypothesized to be associated with the concepts (compliance to medications, keeping medical appointments and regular medical checkups). The third dimension, consequences of uncontrolled blood sugar level, also included most of the items that were originally hypothesized to be associated with complications of prolonged uncontrolled high/low blood sugar levels such as heart attack, stroke, kidney problems, shaking, confusion, behavioural changes, sweating, eye problem or even blindness.
Secondly, for all the items, the items that were unfamiliar and newer (physical activities, Self Blood Glucose Monitoring (SBGM), and glycosylated haemoglobin $\left(\mathrm{HbA}_{1 \mathrm{C}}\right)$ had lower percent correctness $(\% \mathrm{C})$ than those associated with more traditional aspects (diet, blood pressure monitoring, and medication related items) of self-care management. This is evidenced in low \%C value in component $1(43.5 \%)$ as compared with component $2(70.0 \%)$. Component 1 had items that contained most of the unfamiliar and newer aspects of self-care management and component 2 had items that contained most traditional aspects of the management. Furthermore, the low item-tototal correlation coefficient (0.28) for component 2 as against (0.36) for component 1 supported the above mentioned issue, as items in component 2 had high \%C which permitted little variability thereby causing a low item-to-total correlation. This suggests that patients distinguished between newer and unfamiliar care activities and traditional care activities. Even though respondents scored high in items related to traditional services, they did not automatically score similarly high marks in less familiar items. In other words, they viewed the newer and unfamiliar items differently from traditional items.

Thirdly, the three components identified by the factor analysis were very distinct. This was seen in the low number of dual high factor loadings. Ideally, each factor should measure a unique construct that is distinct from others. In other words, an item should load high on one scale and low on the others. Factor loadings averaged 0.62 for the total items; averages ranged from 0.59 to 0.68 among the three subgroups. This gave credence to the validity of this instrument as items with factor loadings greater than or equal to 0.40 were considered significant, and loadings of 0.50 or greater were considered "very significant. The overall average of $\% \mathrm{C}(55.6 \%)$ and item-to-total correlation coefficient (0.33) also confirmed the construct validity of this instrument as 
their values were desirable. Given that diabetic education on self-care practices is relatively new in Nigeria, one should expect the overall average percent correctness (\%C) and item-to-total correlation coefficient to be low.

The DSCKQ-30 achieved a Cronbach's coefficient $\alpha$ of 0.89 , indicating reliability; component 1 (18 items), component 2 (8 items) and component 3 (4 items) had Cronbach's coefficients $\alpha$ of $0.82,0.74$, and 0.64 respectively (Tables $2 a, 2 b, 2 c$ ). Because reliability is a function of the length of the test, it was expected that scales with smaller number of items would result in a lower, albeit adequate, reliability coefficient.

Considering item-to-total correlation coefficients, percent correctness, factor loadings and Cronbach's coefficients of the extracted components, this study revealed that knowledge of modifiable lifestyle, compliance and adherence to self-care activities and consequences of uncontrolled blood sugar levels are interrelated. Due to this interdependence, there is need for a holistic approach while organizing educational program.

Health professional who will use DSCKQ-30 for "before and after" survey are cautioned that the results need to be analyzed using appropriate statistical techniques. Simple comparisons of raw numbers may lead to incorrect interpretations of the survey results. More analysis is needed to determine a meaningful difference in scores to pinpoint with confidence exactly which areas of patients' self-care knowledge most urgently require improvement. Thus, DSCKQ-30 could be used in practice as a quality assurance tool. Patients could be surveyed at regular intervals to ensure that there is no deterioration in their knowledge of self-care activities over time.

This DSCKQ-30 identified differences in some patients' demographic characteristics such as "having family members, relatives or friends with diabetes" (t-test $=6.606 ; p<$ $0.0001)$ and "duration of diabetes" ( $F=$ 3.453; $p=0.0169$ ) were significantly associated with mean score of patients' knowledge of self-care practices, these areas should be explored and exploited. Duration of diabetes of majority of the respondents was less than five years, and this group of patients was less likely to be knowledgeable than the respondents with duration of diabetes of more than six years. This might be associated with insidious nature of diabetes. Respondents with lower duration of diabetes might not see the need to self care until the symptoms are manifested, unlike patients who had lived with the disease for many years, whose symptoms had manifested. This later group of patients is more likely to self care to relieve themselves of the debilities and discomforts associated with diabetes. There is need to intensify self care training for the patient's family members, relatives or friends, also for newly diagnosed patients and asymptomatic patients to prevent and reduce the development and progression of diabetes complications.

Educational status of the patients was not significantly associated with the mean score of patients' knowledge of self-care practices $(F=2.775 ; p=0.0639)$. Patients that received tertiary education had the lowest standard deviation $( \pm 3.58)$ indicating that their responses clustered to the mean while higher standard deviations in patients that stopped at primary $( \pm 6.07)$ and secondary $( \pm 5.27)$ schools reflected high variability of opinions from the mean, which indicated that respondents who got to tertiary education were more likely to be assertive than their primary and secondary school counterparts.

The findings of this study could be helpful to all doctors, pharmacists, diabetic patients, diabetes researchers and other diabetes healthcare team, especially those in developing countries such as those in Africa and Asia which have comparable health care systems and diabetes data to that of Nigeria. 


\section{Limitations}

The following limitations in addition to those mentioned in the text were inherent in the study and the results were interpreted in this light. Data about self-care knowledge were self-reported; however, self-reported data about diabetes status have been established to be both valid and reliable [20]. The sample size was small and the study period was short, although, diabetic patients who came to hospital within study period and satisfied the inclusion criteria were included. However, some potential patients who did not come within the study period were left out. Non response (missing value) bias was a limitation. The remaining cases after deletion might not be the true representative of the responses if there was no missing value.

\section{CONCLUSION}

The instrument used, DSCKQ-30, provided a quantitative measure of patient's knowledge of self-care practices. There is urgent need for the development of similar instruments for other chronic diseases such as HIV/AIDS, cancer, hypertension, asthma and host of others diseases.

\section{ACKNOWLEDGEMENT}

The authors wish to acknowledge the assistance of the staff of Department of Clinical Pharmacy and Pharmacy Management, University of Nigeria, Nsukka, Nigeria, during data collection and analysis.

\section{FUNDING}

No external funding was obtained for the study

\section{CONFLICTS OF INTEREST}

We declare that there is no conflict of interest

\section{REFERENCES}

1. Akanji AO, Adetunji A. The pattern of presentation of foot lesions in Nigerian diabetic patients. West Afr J Med 1990; 9: 1-4.

2. National Diabetes Fact Sheet. American Diabetes Association Web site. Available at: http://www.diabetes.org/main/info/facts/factsna tl.jsp. Accessed December 15, 2002.

3. McLarty DG, Swai ABM, Kitange HM, Masuki G, Mitnangi BL, Kilama PM, Makene I, Chuwa LM. Prevalence of diabetes and impaired glucose tolerance in rural Tanzania, The Lancet1989; 1: 871-875.

4. Greenwood BM, Taylor J. The complications of diabetes in Nigerians. Tropical Geographic Medicine 1968; 20: 1-12.

5. Adetuyibi A. Diabetes in the Nigerian African. Review of long term complications. Tropical Geographic Medicine 1976; 28: 155-159.

6. Federal ministry of health in collaboration with WHO, EC, DFID. Standard treatment guidelines, Nigeria, 2008: 90-97.

7. National Diabetes Support Team. Diabetes and Pharmacy Services in England November 2006. Available at: http://www.diabetes.nhs.uk/downloads/diabete s_pharmacy_services.pdf. Accessed December 12, 2008.

8. Department of Health (2006) Improving patients' access to medicines: A guide to implementing nurse and pharmacist independent prescribing within the NHS in England. Available at: http://www.dh.gov.uk/PublicationsAndStatistics /Publications/PublicationsPolicyAndGuidance/ PublicationsPolicyAndGuidanceArticle/fs/en?C ONTENT_ID=4133743\&chk=HSzl1/. Accessed December 12, 2008.

9. Royal Pharmaceutical Society of Great Britain (RPSGB) (2006) Medicines, Ethics and Practice. Available at: http://www.rpsgb.org.uk. Accessed December 12, 2008.

10. Royal Pharmaceutical Society of Great Britain (RPSGB) (2006) National resources available to support the community pharmacy contract. Available at: http://www.rpsgb.org.uk. Accessed December 12, 2008.

11. Mensing $C$, Boucher J, Cypress $M$, Weinger $K$, Mulcahy K, Barta P, Hosey G, Kopher W, Lasichak A, Lamb B, Mangan M, Norman J, Tanja J, Yauk L, Wisdom K, Adams C. National standard for diabetes self management education. Diabetes Care 2004; 27(1): S143-S150.

12. Brown SA: Effects of educational interventions in diabetes care: a meta-analysis of findings. Nurs Res 1988; 37: 223-230.

13. Brown SA: Studies of educational interventions and outcomes in diabetic adults: a meta-analysis revisited. Patient Educ Couns 1990; 16: 189215. 
Adibe et al

14. Beggan MP, Cregan D, Drury MI: Assessment of the outcome of an educational programme of diabetes self-care. Diabetologia 1982; 23: 246-251.

15. Dunn S, Beeney LJ, Hoskins PL, Turtle JR. Knowledge and attitude change as predictors of metabolic improvement in diabetes education. Soc Sci Med 1984; 31: 1135-1141.

16. Flaskerud $\mathrm{JH}$ : Is the Likert scale format culturally biased? Nurs Res 1988; 37: 185-186.

17. Toobert DJ, Hampson SE, Glasgow RW. The Summary of Diabetes Self-Care Activity Measure. Diabetes Care 2000; 23: 943-950.
18. National Population Commission (NPC) (2006), Population Census 2006.

19. Garcia $A A$, Villagomez ET, Brown $S A$, Kouzekanani K, Hanis CL. The Starr County Diabetes Education Study: Development of the Spanish-language diabetes knowledge questionnaire. Diabetes care January 2001; 24(1): 16-21.

20. West JD, Goldberg KL. Diabetes Self-Care Knowledge among Outpatients at a Veterans Affairs Medical Center. Am J Health-Syst Pharm. Available at: www.medscape.com/ viewpublication/74. Accessed June 11, 2009. 